\title{
Kapuscinski: guia para uma análise crítica das notícias sobre conflitos internacionais
}

Dolors Palau Sampio

Doutora em Jornalismo pela Universidade Autônoma de Barcelona.

Professora de Jornalismo da Universidade de Valência, Espanha.

E-mail: dolors.palau@uv.es

Resumo: Este artigo propõe, através da obra do jornalista Ryszard Kapuscinski, uma aproximação crítica à cobertura dos conflitos internacionais. Após defender uma educação para os meios de comunicação, mostra a necessidade de se refletir sobre as carências e limitações desse tipo de tratamento da informação. Para tanto, toma os textos de Kapuscinski como pedra de toque de um jornalismo que mescla disciplinas e gêneros, que vai além das cifras inumanas e do impacto pontual, para descobrir as verdadeiras raízes de tais conflitos e dar voz e rosto às suas realidades humanas.

Palavras-chave: imprensa, cobertura de conflitos, Terceiro Mundo, jornalismo e literatura.
Abstract: This paper deals about a critical approach to international conflicts information, according to Ryszard Kapuscinski's work. After claiming for a media's education, it proposes the necessity of reflecting on news' treatment limitations. In consequence, it also incorporates Kapuscinski's texts as a model of an hybrid journalism that combines different genres and disciplines, in order to offer a comprehensive information over the merely statistics data, discovering the deep and real reasons of these conflicts.

Keywords: information treatment, conflict, Third World, literacy and journalism.

Nos anos de 1960 e 1970, Ryszard Kapuscinski (Pinsk, Bielorrússia, 1932/ Varsóvia, Polônia, 2007) cobriu, como correspondente da Agência de Imprensa Polonesa (Polska Agencja Prasowa), o processo de descolonização do continente africano; no início da década de 1980, reconstituiu a queda do Xá no Irã, após a revolução islâmica de Khomeini, e, na de 1990, testemunhou a desintegração da URSS - União das Repúblicas Socialistas Soviéticas -, em repúblicas independentes. Atualmente, os países sobre os quais o jornalista testemunhou, os conflitos aos quais deu voz e rosto, continuam ocupando ainda as páginas dos jornais, como se o tempo houvesse passado em vão. República Democrática do Congo, Uganda, Ruanda, Nigéria, Etiópia, Irã, Chechênia e Cazaquistão, entre 
comunicação \& educação • Ano XIV • Número 2 • maio/ago 2009

1. Destacam-se, em espanhol, os seguintes títulos El Sha (O Xá): E Emperador (Ed. bras.: O Imperador: a queda de um autocrata. Tradução: Tomasz Barcinski. São Paulo: Companhia das Letras, 2005. 200 p.); La guerra del fútbol ( $E d$ bras.: A guerra do futebol. 1. ed. São Paulo: Companhia das Letras, 2008. 280 p.); El Imperio (Ed. bras.: Imperium Tradução: Ana Lúcia Mikosz, Kenneth Hacynski da Nóbrega. São Paulo: Companhia das Letras, 1994. 320 p.); Ébano (Ed. bras.: Ébano: minha vida na África. Tradução: Tomasz Barcinski. São Paulo: Companhia das Letras, 2002. 360 p.); Un día más con vida o Viajes con Heródoto (Ed. bras.: Minhas viagens com $\mathrm{He}$ ródoto: entre a história $e$ o jornalismo. Tradução: Tomasz Barcinski. São Paulo: Companhia das Letras, 2006. 312 p.); além de coletâneas de artigos (Lapidarium IV); reflexões (Los cinco sentidos de periodista - estar, ver, oír, compartir, pensar), em coedição com o Fondo de Cultura Económica e Fundación para un Nuevo Periodismo Iberoamericano (Ciudad do México, 2004. 90 p.); e o livro-entrevista Los cínicos no sirven para este oficio (Ed. port.: Os cínicos não servem para este ofício. Tradução: Sandra Escobar. Lisboa: Relógio d'Água, 2008).

2. SANCHO, J. M. Medios de comunicación, sociedad de la información aprendizaje y comprensión: piezas para un rompecabezas. In: BALLESTA, J.; SANCHO, J. Maria; AREA MOREIRA, M. Los medios de comunicación en el currículum $(\mathrm{Os}$ meios de comunicação no currículo). Múrcia: KR, 1998. p. 19.

3. Ibid., p. 37. outros, surgem esporadicamente na capa dos jornais como protagonistas de lutas armadas, atos terroristas e escassez de alimentos; porém, com frequência, aparecem reduzidos à frieza dos dados, traduzidos sob a forma de cifras inumanas que só fazem alimentar os estereótipos, estigmatizar as pessoas e impermeabilizar as consciências de leitores e espectadores do hemisfério norte-ocidental. Entretanto, ante essa espetacularização de impacto, desativadora, que se impôs na imprensa, a qual busca tão só a emoção do momento e anula a reflexão, existem também, no campo do jornalismo, olhares compreensivos sobre os conflitos do mundo. Um deles é o olhar de Kapuscinski, empenhado em trazer à luz as raízes profundas que alimentam esses conflitos, sem esquecer que, por trás dos números, ocultam-se realidades humanas.

A obra de Kapuscinski ${ }^{1}$ constitui uma referência, um modelo de jornalismo ético, responsável e intencional diante do distanciamento supostamente objetivo, comprometido em romper as fronteiras de uma mentalidade eurocêntrica para dar conta do outro, a partir da complexidade de suas circunstâncias. Um jornalismo documentado e analítico, consciente, que renuncia ao tratamento epidérmico, tecido, além do mais, com o vime da melhor literatura, o da palavra precisa. Nesse sentido, o trabalho do jornalista polonês torna-se interessante como material didático, não apenas pela transversalidade curricular que permite, como também pela variedade de propostas pedagógicas que pode inspirar.

\section{A NECESSIDADE DE EDUCAR PARA OS MEIOS DE COMUNICAÇÃO}

A preocupação da escola com os meios de comunicação foi aumentando à medida que tais meios - principalmente a televisão - ganhavam peso e tempo no processo de socialização, em detrimento de uma instituição escolar que não só "não é a única que intervém no processo de educação, como ainda, com frequência, nem sequer é 'a mais influente"'². A necessidade de estudar os meios de comunicação de massa em distintas etapas da educação começou a se manifestar há quatro décadas, mas somente em meados de 1980 foi outorgado à escola o papel de desenvolver os modos de interpretação e as ferramentas de pensamento que permitissem ao aluno selecionar, analisar e dar sentido à informação recebida ${ }^{3}$.

Area Moreira recorre a três suposições que sustentam a integração curricular da educação para os meios de comunicação: a poderosa influência dos meios na configuração de valores e atitudes, a escassa atenção das escolas a esse fenômeno e a contribuição à formação democrática dos cidadãos ${ }^{4}$. As propostas lançadas nos últimos tempos incidem sobre estes aspectos, conscientes de que os meios de comunicação são um espaço e um motor de poder em escala mundial $\mathrm{e}$ que apenas mediante uma atitude crítica e seletiva, configurada desde os primeiros anos de educação, será possível colocar a nosso serviço as funções de tais meios ${ }^{5}$. Domingo vai além e fala em "alfabetizar criticamente" ${ }^{6}$ na linguagem dos meios 
de comunicação, superando as atrações exacerbadas e as fobias que podem suscitar as tecnologias da comunicação.

O desafio é desenvolver estratégias motivadoras para envolver os alunos nos processos de análise dos valores, intenções e estratégias de comunicação, que os transformam em agentes da própria educação e não mais em meros objetos dela. Por este ponto de vista, Domingo sustenta que o valor pedagógico não é intrínseco aos meios de comunicação, já que é dado pelo contexto metodológico: como objeto de estudo, para conhecer seu funcionamento; como suporte de informação e recurso didático, para aprender com a mídia, e como meio de expressão e criação ${ }^{7}$. A isso se deve acrescentar uma quarta linha: seu uso como material linguístico, através da observação ou análise de suas características textuais ${ }^{8}$.

Area Moreira afirma que a opção de formação mais promissora é a introdução do uso crítico dos meios de comunicação como tema transversal em todo o currículo, posto que isto possibilitaria a superação das limitações das disciplinas tradicionais, ao passo que conecta a aprendizagem em sala de aula com a experiência cotidiana dos alunos ${ }^{9}$.

\section{CONHECER OS MEIOS DE COMUNICAÇÃO E SEU FUNCIONAMENTO}

A primeira condição para a realização de uma leitura crítica dos meios de comunicação é conhecer as suas características formais, isto é, alfabetizar os estudantes - neste caso - no domínio da linguagem da imprensa escrita. Isso implica introduzir as chaves para o entendimento dos mecanismos de pesquisa, seleção e hierarquização das informações, bem como a plasmação destas na superfície da publicação - algo fundamental em uma seção como a internacional, em que a falta de cobertura da mídia condena muitos países à invisibilidade, da qual, frequentemente, apenas surgem quando ocorre uma catástrofe. Para tanto, em uma aproximação do geral ao particular, é necessário compreender a distribuição do jornal em seções, em características e funções dos gêneros que estão presentes nelas e como estão configuradas, desde a confecção das manchetes até a extensão do texto, passando pela estrutura deste ou a presença de fotografias. Um segundo nível de leitura comparada ou em profundidade exigiria o detalhamento das fontes de informação, o léxico empregado ou os elementos que refletem uma interpretação mais ou menos explícita.

Entretanto, como aponta Area Moreira ${ }^{10}$, não basta um enfoque gramaticalista, que ensine a identificar o que é uma notícia e um artigo opinativo, tampouco é suficiente um enfoque centrado na tecnologia ou nas dimensões técnico-materiais, no manejo dos equipamentos - que muitas vezes tem dominado a educação para os meios audiovisuais; é antes necessária a complementaridade de ambos os enfoques, através de uma abordagem de caráter socioideológico, destinada a identificar e explicitar as mensagens difundidas. Portanto, uma educação para
4. AREA, M. La educación para los medios de comunicación en el currículum escolar (A educação para os meios de comunicação no currículo escolar). In: BALLESTA, J.; SANCHO, J. Maria; AREA MOREIRA, M. Los medios..., cit., p. 49-52.

5. CASSANY, D.; LUNA, M.; SANZ, G. Ensenyar llengua (Ensinar língua). Barcelona: Graó, 1993. p. 521.

6 DOMINGO, J. Educar ciudadanos críticos con los medios de comunicación (Educar cidadãos críticos com os meios de comunicação), Comunicar, n. 21, p. 104, 2003.

7. Ibid.

8. CASSANY, D.; LUNA M.; SANZ, G. Ensenyar llengua, cit., p. 528.

9. AREA, La educación para los medios..., cit., p. 53-55.

10. Ibid., p. 59-62. 
comunicação \& educação • Ano XIV • Número 2 • maio/ago 2009

11. Ibid., p. 71.

12. APARICl, R. La enseñanza de los medios (O ensino da mídia). Cuadernos de Pedagogía, $\mathrm{n}$. 241, p. $12,1995$.

13. MASTERMAN, L. La enseñanza de los medios de comunicación ( $\mathrm{O}$ ensino dos meios de comunicação). Madrid: Ediciones de la Torre, 1993.

14. MORERA, M. El periódico, un proyecto didácti$\mathrm{CO}$, social e individual $(\mathrm{O}$ jornal, um projeto didático, social e individual). Cuadernos de Pedagogía, n. 267, p. 38-41, 1998.

15. VENTURA, J. A.; BUENO, F. G. Valores, a través de la prensa (Valores, através da imprensa). Cuadernos de Pedagogía, n. 248, p. 42-46, 1996.

16. BASTIDA, A.; TRIBÓ, G. Guerra y subdesarrollo. O el caso de Somália (Guerra e subdesenvolvimento ou o caso da Somália). Cuadernos de Pedagogía, n. 249, p. 84-87, 1996. os meios de comunicação deveria ser implantada de acordo com um modelo que desenvolvesse os seguintes conceitos:

1) Todos os meios de comunicação são fabricações.

2) Todos os meios de comunicação constroem uma realidade.

3) Os públicos constroem o significado dos meios de comunicação.

4) Os meios de comunicação têm implicações comerciais.

5) Os meios de comunicação contêm mensagens ideológicas e de valores.

6) Os meios de comunicação têm implicações sociais e políticas.

7) Os meios de comunicação possuem uma forma estética única, intimamente relacionada com seu conteúdo ${ }^{11}$.

Aparici, por sua vez, defende uma metodologia que integre as perspectivas anteriores e incorpore uma nova, a da produção: "Teríamos que colocar os alunos em situação de comunicação. Não somente para realizarem uma produção, mas também para que a analisassem como emissores quanto à forma, o fundo, os objetivos, o público etc." ${ }^{2}$.

Em torno de tais reflexões, foram lançadas várias propostas de trabalho em sala de aula, seguindo, em grande medida, o rastro das reflexões teóricas de Masterman $^{13}$, fundamentalmente a partir dos meios audiovisuais. No caso da mídia escrita, surgiram propostas, entre outras iniciativas, de oficinas de jornalismo ou de elaboração de um jornal escolar ${ }^{14}$, e até aquelas centradas no tratamento das informações, seja para analisá-las em profundidade, reescrevê-las, seja para estabelecer um debate sobre os temas abordados. É o caso das atividades sugeridas por Ventura e Bueno ${ }^{15}$, destinadas a promover a educação em valores, ou por Bastida e Tribón ${ }^{16}$, sobre a guerra e o desenvolvimento.

\section{UMA OBRA NA FRONTEIRA ENTRE O JORNALISMO E A LITERATURA}

Kapuscinski, bacharel em História pela Universidade de Varsóvia e estudante de Jornalismo na Polônia, estreou como correspondente em 1956, na Índia, e durante um quarto de século foi testemunha de exceção dos principais acontecimentos políticos sociais da África, Ásia e América Latina. Desde essa época, o repórter polonês tem transformado sua rica experiência em livros que mesclam o melhor da literatura e do jornalismo, em relatos de não ficção nos quais se apaga a linha que separa gêneros e disciplinas, em textos que se apresentam como reportagem e crônica, mas também como ensaio, e no qual se fundem a História e a Sociologia. As razões que motivaram essa escrita são as que dão sentido à escolha de suas obras como proposta didática:

Conheci os países do Terceiro Mundo como correspondente de uma agência polonesa e enviava notícias constantemente. Disse para mim mesmo: isto que eu estou escrevendo não reflete a realidade. Nas notícias dos jornais operamos entre 600 e 800 palavras. É uma linguagem pobre e superficial, incapaz de refletir o que se escuta e o que se sente. Então comecei a escrever meus livros passo a 
passo, como se fossem um segundo volume de tudo o que havia escrito como correspondente durante anos. Nesse segundo volume escrevi o que não havia podido contar no primeiro [...]. Nunca me preocupei em saber qual era o gênero que eu estava usando para contar o que queria ${ }^{17}$.

As obras de Kapuscinski não são meras compilações de textos procedentes de jornais, mas a reescrita daquelas experiências que, liberadas das amarras expressivas da imprensa (espaço, impessoalidade, funcionalidade...), vieram à luz através da hibridação de gêneros, da narração literária dos fatos de não ficção, do relato poético sujeito às normas da referencialidade jornalística. Precisamente nisso reside seu valor como pedra de toque para a promoção de uma leitura crítica do tratamento que os meios de comunicação dão aos conflitos internacionais, como contraponto para conhecer outra forma de jornalismo, como espelho no qual contrasta o discurso informativo tradicional.

Este artigo propõe, dando um passo além da análise habitual da mídia no contexto escolar, uma reflexão aprofundada sobre as próprias limitações expressivas da imprensa, no momento de informar fatos distantes geográfica e culturalmente, e, ao mesmo tempo, sobre as difusas fronteiras entre jornalismo e literatura. Bastida, Bordons e Rins ${ }^{18}$ destacam a capacidade do texto literário como instrumento para a abordagem das consequências dos conflitos armados, na medida em que implica um modo de ver as coisas com os olhos do outro.

Todos esses elementos conferem à obra de Kapuscinski um valor agregado como material didático na área de Literatura, já que não somente permite incorporar ao currículo textos excluídos tradicionalmente do cânone - apesar de que, neste caso, tenham circulado originalmente como livro -, mas também porque ela oferece uma referência interessante para analisar os recursos que intervêm na construção do relato. Os textos propostos unem os ingredientes necessários para aceder às competências literárias que devem ser adquiridas, de acordo com Bertochi, no Ensino Médio, quais sejam, as de tipo afetivo, cognitivo, linguístico e metalinguístico ${ }^{19}$.

Os objetivos afetivos, centrados no gosto pela leitura ou na tomada de consciência do significado do texto literário - através das sensações experimentadas -, vêm da mão de um dos relatos que, apesar de não estarem entre os que costumeiramente são lidos pela maioria dos adolescentes, podem ser sedutores por seu componente do acaso, do épico, nas ocasiões de risco, inerentes ao trabalho do correspondente em zonas de conflito. Neste caso, o caráter autobiográfico das experiências, devidamente introduzido pelos docentes, pode ser um trunfo a favor do interesse dos alunos.

Os objetivos cognitivos estão presentes em tudo o que implica a aquisição de habilidades propriamente literárias - previsão, inferência, comparação etc. -, mas também, dadas as características da obra, na provisão de conhecimentos geográficos, históricos e antropológicos, desde a localização dos países até seus condicionantes físicos, sua estrutura social ou sua evolução política ao longo do tempo.
17. Entrevista de Ryszard Kapuscinski, em El País Semanal, 5 jan. 2003.

18. BASTIDA, A.: BORDONS, G.; RINS, S. Fer reflexionar sobre els conflictes del món a partir de la literatura (Para refletir sobre os conflitos do mundo a partir da literatura). In: BORDONS, G. DÍAZ-PLAJA, A. (Coords.). Ensenyar literatura a secundària (Ensinar literatura no Ensino Médio). Barcelona: Graó, 2004 p. 71-94.

19. Apud: LLUCH, G. Del relat audiovisual al literari (Do relato audiovisual ao relato literário). In: BORDONS, G.; DÍAZ-PLAJA A. (Coords.). Ensenyar literatura a secundària, cit., p. 140-142. 
20. CHILLÓN, A. Literatura y periodismo. Una tradición de relaciones promiscuas (Literatura e jornalismo: uma tradição de relações promíscuas). Bellaterra: Universitat Autònoma de Barcelona/ Servei de publicacions. 1999. p. 305
Através da narrativa de Kapuscinski, também é possível alcançar os objetivos linguísticos e metalinguísticos propostos, relativos à estrutura do texto e aos elementos que compõem a construção literária, desde a caracterização dos personagens e cenários, até a configuração da trama, o tipo de narrador e o ponto de vista. Essa análise pode ser enriquecida se for abordada sob a ótica das sinergias entre jornalismo e literatura, de como as ferramentas desta última, longe de trazer artificialidade, contribuem para que o jornalismo seja capaz de maior reflexão, de maior precisão na abordagem das realidades expostas, superando a linguagem pobre e artificial à qual se referia o jornalista. Como indica Chillón, Kapuscinski cultiva um tipo de jornalismo literário inclassificável, que:

[...] conjuga, em uma simbiose inédita, as técnicas documentais próprias do jornalismo investigativo, o exercício de observação característico da crônica e a procura de uma espécie de verdade poética transcendente, mediante procedimentos de fabulação mais próximos da lenda, do apólogo e do conto que do romance realista e das limitações inerentes à simples verdade documental ${ }^{20}$.

\section{PROPOSTA DE TRABALHO EM SALA DE AULA}

Se uma das prioridades é a formação crítica e expressiva para a abordagem da complexidade dos conflitos do Terceiro Mundo, o primeiro passo deverá ser a familiarização com a seção internacional, na qual aparecem publicadas as informações a serem analisadas. Portanto, deverá ser feita uma pesquisa e um esquema dos textos publicados, para ver a presença, em termos quantitativos, dos diferentes países, os conteúdos que despertam interesse informativo e por quanto tempo eles mantêm tal interesse. Além disso, é interessante introduzir uma caracterização dos diversos gêneros que aparecem publicados, isto é, se se trata de notícias de agências, de crônicas de um correspondente, de reportagens que oferecem uma visão de conjunto ou de artigos opinativos, e de que modo cada um deles contribui para a configuração da realidade apresentada. Nesse ponto, será possível identificar uma série de problemas coincidentes nos vários países que enfrentam conflitos bélicos ou sociais; será possível ainda, através dos elementos trazidos, estabelecer um termo de comparação entre o tratamento da imprensa diária de informação geral e aquele que é dado pelo jornalista polonês.

A segunda fase começaria com a leitura de alguma das obras de Kapuscinski, apesar de que, dada a estrutura aberta, é admissível optar pela combinação de diferentes capítulos, seguindo alguma relação temática ou geográfica. A atenção deve centrar-se principalmente em responder a duas questões intimamente ligadas: o que conta o jornalista? E, sobretudo, de que forma ele conta? Se a pergunta inicial coloca em questão os pontos de atenção do correspondente, a segunda permite o aprofundamento no tratamento dos gêneros e na fronteira entre jornalismo e literatura. Nesse sentido, o objetivo é identificar quais recursos ele utiliza e de que modo estes, distantes do que é habitual no jornalismo de 
informação geral, ajudam a entender melhor uma realidade complexa e desconhecida. Em Ébano ${ }^{21}$, por exemplo, elementos próprios do discurso literário tornam-se centrais, como a descrição de ambientes e de personagens, a recriação de diálogos e situações, ou a apreciação do detalhe, através do olhar direto do cronista que conhece em primeira mão aquilo que conta e é capaz de incorporar à voz daqueles que habitualmente não a tem no jornalismo convencional. Entretanto, longe de transformar seu relato em uma coleção de histórias ou de impressões soltas, Kapuscinski mostra habilidade em transcender o detalhe com a capacidade de observação de um antropólogo, com a contextualização lúcida de um historiador ou a precisão analítica de um ensaísta. Tudo isso para oferecer uma rica tapeçaria, distante de uma visão esquemática e simplificadora, que encontramos diariamente na mídia.

A tudo isso se pode somar uma última etapa que transforme o estudante em narrador dessa realidade que Kapuscinski aborda em suas obras, através do contato com quem viveu essas experiências em primeira pessoa. Trata-se de colocar os alunos em situação de comunicação, como diz Aparicii ${ }^{22}$, para escrever uma reportagem na qual devem estar refletidos a bagagem e os dados reunidos. Com esta proposta, completa-se um ciclo que vai da pesquisa e análise da informação ao conhecimento direto das realidades midiáticas; da leitura e do debate teórico à reflexão e plasmação pela escrita na reportagem; da experiência de pessoas deslocadas por conflitos - que até então careciam, pelo menos a maioria delas, de voz e rosto - a suas últimas consequências.

\section{REFERÊNCIAS BIBLIOGRÁFICAS}

APARICI, R. La enseñanza de los medios (O ensino da mídia). Cuadernos de Pedagogía, n. 241, 1995.

AREA MOREIRA, M. La educación para los medios de comunicación en el currículum escolar (A educação para os meios de comunicação no currículo escolar). In: BALLESTA, J.; SANCHO, J. Maria; AREA MOREIRA, M. Los medios de comunicación en el currículum (Os meios de comunicação no currículo). Múrcia: KR, 1998.

BASTIDA, A.; TRIBÓ, G. Guerra y subdesarrollo. O el caso de Somália (Guerra e subdesenvolvimento ou o caso da Somália). Cuadernos de Pedagogía, n. 249, 1996.

BASTIDA, A.; BORDONS, G.; RINS, S. Fer reflexionar sobre els conflictes del món a partir de la literatura (Para refletir sobre os conflitos do mundo a partir da literatura). In: BORDONS, G.; DÍAZ-PLAJA, A. (Coords.). Ensenyar literatura a secundària (Ensinar literatura no Ensino Médio). Barcelona: Graó, 2004.

CASSANY, D.; LUNA, M.; SANZ, G. Ensenyar llengua (Ensinar língua). Barcelona: Graó, 1993.
21. KAPUSCINSKI, Ryszard. Ébano, cit.

22. APARICl, La enseñanza de los medios, cit. 
comunicação \& educação • Ano XIV • Número 2 • maio/ago 2009

CHILLÓN, A. Literatura y periodismo. Una tradición de relaciones promiscuas (Literatura e jornalismo. Uma tradição de relações promíscuas). Bellaterra: Universitat Autònoma de Barcelona/Servei de publicacions, 1999.

DOMINGO, J. Educar ciudadanos críticos con los medios de comunicación (Educar cidadãos críticos com os meios de comunicação). Comunicar, n. 21, 2003.

KAPUSCINSKI, Ryszard. Imperium. Tradução: Ana Lúcia Mikosz, Kenneth Hacynski da Nóbrega. São Paulo: Companhia das Letras, 1994.

Ébano: minha vida na África. Tradução: Tomasz Barcinski. São Paulo: Companhia das Letras, 2002.

. O imperador: a queda de um autocrata. Tradução: Tomasz Barcinski. São Paulo: Companhia das Letras, 2005.

. Minhas viagens com Heródoto: entre a história e o jornalismo. Tradução: Tomasz Barcinski. São Paulo: Companhia das Letras, 2006.

. A guerra do futebol. 1. ed. São Paulo: Companhia das Letras, 2008.

. Os cínicos não servem para este ofício. Tradução: Sandra Escobar. Lisboa: Relógio d'Água, 2008.

LLUCH, G. Del relat audiovisual al literari (Do relato audiovisual ao relato literário). In: BORDONS, G.; DÍAZ-PLAJA, A. (Coords.). Ensenyar literatura a secundària (Ensinar literatura no Ensino Médio). Barcelona: Grão, 2004.

MASTERMAN, L. La enseñanza de los medios de comunicación ( $\mathrm{O}$ ensino dos meios de comunicação). Madrid: Ediciones de la Torre, 1993.

MORERA, M. El periódico, un proyecto didáctico, social e individual ( $\mathrm{O}$ jornal, um projeto didático, social e individual). Cuadernos de Pedagogía, n. 267, 1998.

SANCHO, J. Maria. Medios de comunicación, sociedad de la información, aprendizaje y comprensión: piezas para un rompecabezas. In: BALLESTA, J.; SANCHO, J. Maria; AREA MOREIRA, M. Los medios de comunicación en el currículum (Os meios de comunicação no currículo). Múrcia: KR, 1998.

VENTURA, J. A.; BUENO, F. G. Valores, a través de la prensa (Valores, através da imprensa). Cuadernos de Pedagogía, n. 248, 1996. 